\title{
Analysis of In Vitro Effects of Sex Steroids on Lymphocyte Responsiveness in Murrah Buffaloes (Bubalus bubalis)
}

\author{
Zahoor Ahmad Pampori and Sujata Pandita \\ Dairy Cattle Physiology Division, National Dairy Research Institute (ICAR), Haryana, Karnal 132001, India \\ Correspondence should be addressed to Zahoor Ahmad Pampori, drzap64@gmail.com
}

Received 5 November 2011; Accepted 13 February 2012

Academic Editor: Daniel Smeak

Copyright ( 2012 Z. A. Pampori and S. Pandita. This is an open access article distributed under the Creative Commons Attribution License, which permits unrestricted use, distribution, and reproduction in any medium, provided the original work is properly cited.

\begin{abstract}
Present study was carried out on forty four apparently healthy Murrah buffaloes of different age groups of both sexes to investigate the effects of sex steroids on cell mediated immunity in vitro. Estrogen inhibited proliferation in mitogen-stimulated lymphocytes from prepubertal but not post pubertal buffaloes of either sex. Estrogen at $100 \mathrm{pg} / \mathrm{mL}$ concentration stimulating the proliferation significantly $(P<0.05)$. in all groups and had higher stimulatory effect in lymphocytes from day 10 than day 0 of estrous cycle. Progesterone inhibited lymphocyte proliferation, and inhibition was directly related to the dose, in all groups of either sex. Testosterone did not inhibit proliferation at any dose level and did not show any consistent and lucid effects on lymphocyte proliferation. Present study revealed that buffalo lymphocytes produce appreciable amounts of NO in culture system after treatment with estradiol. Significantly high levels of NO in culture supernatant were found in prepubertal buffalo calves and least in post pubertal buffaloes, which had an inverse relation with lymphocyte proliferation in presence of estradiol. NO in culture supernatant was high at the lowest dose of progesterone which was proportional to the lymphocyte proliferation when treated with progesterone. No significant difference in NO culture supernatant was observed between different concentrations of testosterone treatment.
\end{abstract}

\section{Introduction}

The sex steroids are in use for the last more than a millennium to correct reproductive disorders and augment reproductive efficiency in animals. However, it has been increasingly apparent that the effects of sex hormones extend far beyond their predominant role in sexual differentiation and reproduction and are now being realised as integral signalling modulators of mammalian immune system. Sexual dimorphism in disease incidence and host response in wide range of animal species provides an indirect evidence of role of sexual hormones in immune modulation [1-3]. Immunological evidence suggests that female sex hormones play a role in the aetiology and course of chronic inflammatory diseases [4]. The number and activity of immune cells in reproductive tract of animals and humans vary significantly throughout the phases of the reproductive cycle and are believed to be controlled by changes in the levels of estradiol and progesterone hormones [5-7]. Ramadan et al. [8] in sheep and Wulster-Radcliffe et al. [9] in gilts have reported higher resistance to uterine infections at oestrus and least during luteal phase. Lymphocyte proliferation response, a promising marker of host immunity, has been reported to exhibit variability during various physiological and reproductive phases in different animal species $([10,11]$ in dairy cattle; [12] in hamsters) that has been attributed to sex hormones. Use of sex steroids or sex steroid blockers or ovariectomy or castration in animal models for studying the pathophysiology and immunoendocrinology has provided direct evidence for the role of sex steroids in immune modulation $[13,14]$. Since there existed species variation in immune responses to sex steroids, present study was taken up in buffaloes of different age, sex, and reproductive phase wherein phytohemagglutinin- (PHA-) stimulated lymphocytes were exposed to different concentrations of estrogen, progesterone, and testosterone to analyse the influence of 
these steroids on proliferation response and nitric oxide production, which probably is the first study of its kind in buffaloes.

\section{Materials and Methods}

Forty-four apparently healthy Murrah buffaloes of three age groups of both sexes (male and female) were selected from NDRI herd for conducting present experiments. Eighteen male buffaloes were divided into 3 groups of 6 buffaloes on the basis of their age. Group-I included buffaloes with age ranging between 11 and 13 months; group-II consisted of buffaloes with age ranging between 22 and 24 months. Group-III had postpubertal buffaloes 34 and 36 months of age. Similarly 18 female buffaloes were grouped exactly the same way as in males except that female post pubertal group had cyclic heifers at day 8-10 of estrous cycle. Eight cyclic heifers were selected and studied on day 0 and day 10 of estrous cycle. The estrum (day 0) was confirmed through rectal palpation by an expert and concerned veterinarian at the farm. All these Murrah buffaloes were maintained under routine management and nutritional practices as followed in the herd at the institute. The animal experiments were acceptable to the ethical standards of the National Dairy Research Institute, Karnal, India vide IAEC no. 23/09-21/11.

The lymphocytes from peripheral blood were isolated as per the method followed by Young et al. [15] with some alterations made by Huozha et al. [16] to suit our requirements. The proliferative response of lymphocytes was analysed using the colorimetric MTT (tetrazolium) assay, as described by [17]. Briefly, about $15 \mathrm{~mL}$ blood was drawn from every animal in heparinised vacutainer tubes from jugular vein, in the morning. Plasma was separated by centrifugation in refrigeration centrifuge at $2000 \mathrm{rpm}$ for 30 minutes. A white buffy coat at the top of red column was harvested in a new sterile polypropylene centrifuge tube (15 mL) containing Dulbecco's phosphate buffered saline, (DPBS) in a ratio of $1: 2 \mathrm{~V} / \mathrm{V}$ and the whole contents were carefully layered over a lymphocyte separation medium (Histopaque-1077) in a ratio of $3: 1 \mathrm{v} / \mathrm{v}$ in another sterile centrifuge tube and centrifuged at $1500 \mathrm{rpm}$ for $40 \mathrm{~min}$ at room temperature to separate the lymphocytes. The lymphocytes in a thin, white layer at the interface were carefully pipetted out into next sterile tube containing $7 \mathrm{~mL}$ DPBS with antibiotics. Lymphocytes were washed twice in DPBS and third time in culture medium by refrigeration centrifugation at $1000 \mathrm{rpm}$ for 10 minutes in each wash. After last wash culture medium was discarded and cells were resuspended in $3 \mathrm{~mL}$ culture medium (RPMI 1640 with 10\% FCS and antibiotics).

Trypan blue dye exclusion method was used to determine the proportion of viable cells in the separated lymphocytes. When the lymphocyte viability was above $95 \%$, the lymphocytes were processed further for culture. Culture of lymphocytes was carried out in 96-well, tissue culture, flat bottom, sterile microplates with lid from Greiner BioOne, Germany. The cells were adjusted to $1 \times 10^{6}$ cells per culture well. The culture medium used in present study was RPMI-1640 from Sigma Chemical Co., St. Louis, MI, USA, supplemented with L-glutamine, sodium bicarbonate, sodium pyruvate, and antibiotics (Penicillin G and streptomycin sulfate and antifungal amphotericin), besides $10 \%$ fetal calf serum. $20 \mu \mathrm{L}$ of phytohemagglutinin (PHA-P) was added per well to yield a concentration of $5 \mu \mathrm{g} / \mathrm{mL}$ of culture medium. $20 \mu \mathrm{L}$ of steroid hormone (working concentration) was added to each well. The final volume in each well after adding mitogen and or sex steroid hormone was made to $200 \mu \mathrm{L}$ with culture medium. Blank wells contained only $200 \mu \mathrm{L}$ of culture medium with no cells, whereas S$\mathrm{M}$ and $\mathrm{S}+\mathrm{M}$ wells contained no mitogen and mitogen, respectively, besides lymphocytes. Every observation was made in triplicate wells. The cells were cultured for 36 hours at $37^{\circ} \mathrm{C}$ in a humidified $\mathrm{CO}_{2}$ incubator $\left(5 \% \mathrm{CO}_{2}\right)$. After 36 hours of incubation, $100 \mu \mathrm{L}$ of culture supernatant was harvested in sterile $1.5 \mathrm{~mL}$ eppendorf tubes and stored at $-20^{\circ} \mathrm{C}$ for estimation of nitric oxide. Equal volume of culture media with supplements, preincubated at $37^{\circ} \mathrm{C}$, was added into the wells. $20 \mu \mathrm{L}$ of the MTT solution $(5 \mathrm{mg} / \mathrm{mL}$ dissolved in DPBS and filtered through $0.22 \mu \mathrm{m}$ Millex-GV filter unit) was added to each well. The plates were again incubated for $4 \mathrm{hr}$ at $37^{\circ} \mathrm{C}$ in humidified $\mathrm{CO}_{2}$ incubator. Thereafter, the supernatant was pipetted out completely without disturbing formazan crystal layer and $150 \mu \mathrm{L}$ of dimethyl sulfoxide (DMSO) was added to each well. After incubating the plate at room temperature for 15 minutes, it was shaken on a microplate shaker and the optical density was read using ELISA reader (Microscan MS-5608A) in dual wavelength measuring system, at a wavelength of $570 \mathrm{~nm}$ and a reference wavelength of $630 \mathrm{~nm}$. Lymphocyte blastogenic response was expressed as Proliferation Index (PI) and was calculated as follows:

$$
\begin{aligned}
\text { Proliferation Index }(\mathrm{PI})= & \text { OD of the mitogen } \\
& \text { stimulated cells/OD of } \\
& \text { the unstimulated cells. }
\end{aligned}
$$

Influence of steroid hormone on lymphocyte blastogenic activity was calculated by dividing optical density of hormone-treated cells with optical density of mitogen-stimulated cells.

Phytohemagglutinin used as a mitogen for proliferation of T-lymphocytes was made in culture medium at $50 \mu \mathrm{g} / \mathrm{mL}$. $10 \mu \mathrm{L}$ of it was used for every $90 \mu \mathrm{L}$ culture medium in each culture well to yield concentration of PHA $5 \mu \mathrm{g} / \mathrm{mL}$. Stock solution of estradiol, progesterone, and testosterone was prepared in ethanol which was diluted with culture medium to working concentrations of $10 \mathrm{ng} / \mathrm{mL}, 5 \mathrm{ng} / \mathrm{mL}, 1 \mathrm{ng} / \mathrm{mL}$, and $100 \mathrm{pg} / \mathrm{mL}$ for estrogen, $10 \mu \mathrm{g}, 5 \mu \mathrm{g}, 1 \mu \mathrm{g}$, and $100 \mathrm{ng}$ for progesterone, and $1000 \mathrm{ng}, 100 \mathrm{ng}, 10 \mathrm{ng}$, and $1 \mathrm{ng} / \mathrm{mL}$ for testosterone. $10 \mu \mathrm{L}$ of working steroid solutions was added to every $90 \mu \mathrm{L}$ culture medium in culture well yielding final concentration of steroids as $1 \mathrm{ng} / \mathrm{mL}, 500 \mathrm{pg} / \mathrm{mL}, 100 \mathrm{pg} / \mathrm{mL}$, and $10 \mathrm{pg} / \mathrm{mL}$ for estrogen, $1000 \mathrm{ng} / \mathrm{mL}, 500 \mathrm{ng} / \mathrm{mL}, 100 \mathrm{ng} / \mathrm{mL}$ and $10 \mathrm{ng} / \mathrm{mL}$ for progesterone, and $100 \mathrm{ng} / \mathrm{mL}, 10 \mathrm{ng} / \mathrm{mL}$, $1 \mathrm{ng} / \mathrm{mL}$, and $0.1 \mathrm{ng} / \mathrm{mL}$ for testosterone. All the steroid hormones, $\beta$-Estradiol, Progesterone ( $\Delta^{4}$-pregnen-3-20-dione) 
TABLE 1: Dose-dependent effect of estradiol $17 \beta$ on lymphocyte proliferation in vitro in Murrah buffaloes of different sex and age.

\begin{tabular}{|c|c|c|c|c|c|c|c|c|}
\hline \multirow{2}{*}{ Age group } & \multirow{2}{*}{ Sex } & \multicolumn{4}{|c|}{ Estradiol $17 \beta$ concentration $(\mathrm{pg} / \mathrm{mL})$} & \multirow{2}{*}{$\begin{array}{c}\text { Sex* } \\
\text { group mean }\end{array}$} & \multirow{2}{*}{ Group mean } & \multirow{2}{*}{ Sex mean } \\
\hline & & 10 & 100 & 500 & 1000 & & & \\
\hline \multirow{2}{*}{ Group-I } & Male & $0.98 \pm 0.03$ & $1.04 \pm 0.04$ & $0.93 \pm 0.04$ & $0.87 \pm 0.04$ & $0.95 \pm 0.02$ & \multirow{2}{*}{$0.95^{\mathrm{B}} \pm 0.01$} & \multirow{2}{*}{$\begin{array}{l}0.97 \pm 0.01 \\
(\text { Male })\end{array}$} \\
\hline & Female & $0.93 \pm 0.03$ & $0.99 \pm 0.02$ & $0.93 \pm 0.02$ & $0.93 \pm 0.02$ & $0.94 \pm 0.01$ & & \\
\hline \multirow{2}{*}{ Group-II } & Male & $0.95 \pm 0.04$ & $1.01 \pm 0.05$ & $0.97 \pm 0.04$ & $0.91 \pm 0.01$ & $0.96 \pm 0.02$ & \multirow{2}{*}{$0.95^{\mathrm{B}} \pm 0.01$} & \multirow{4}{*}{$\begin{array}{l}0.99 \pm 0.01 \\
\text { (Female) }\end{array}$} \\
\hline & Female & $0.93 \pm 0.04$ & $1.01 \pm 0.03$ & $0.96 \pm 0.02$ & $0.83 \pm 0.02$ & $0.93 \pm 0.02$ & & \\
\hline \multirow{2}{*}{ Group-III } & Male & $0.91 \pm 0.02$ & $1.12 \pm 0.06$ & $1.07 \pm 0.05$ & $0.86 \pm 0.05$ & $0.99 \pm 0.03$ & \multirow{2}{*}{$1.04^{\mathrm{A}} \pm 0.01$} & \\
\hline & Female & $0.99 \pm 0.02$ & $1.11 \pm 0.08$ & $1.14 \pm 0.08$ & $1.14 \pm 0.08$ & $1.09 \pm 0.03$ & & \\
\hline \multicolumn{2}{|c|}{ Treatment mean } & $0.95^{\mathrm{b}} \pm 0.01$ & $1.05^{\mathrm{a}} \pm 0.02$ & $1.00^{\mathrm{a}} \pm 0.02$ & $0.93^{\mathrm{b}} \pm 0.02$ & & & \\
\hline
\end{tabular}

Values with superscript a, b within same row and A, B within same column differ significantly $(P<0.05)$. CD at $t 5 \%$ : sex: 0.03 , group: 0.04 , treatment: 0.05 , sex* group: 0.06 and sex* group*treatment: 0.129 .

and Testosterone ( $\Delta^{4}$-androsten-17 $\beta$-ol-3 one), Histopaque 1077, Phytohemagglutinin (PHA-P), Trypan blue, and Thiazolyl Blue Tetrazolium Bromide (MTT) were purchased from Sigma Chemical Co., St. Louis, MI, USA. Dulbecco's Phosphate Buffered Saline (DPBS) was purchased from Himedia Laboratories Pvt. Ltd. India.

Plasma nitric oxide was estimated as total nitrite $\left(\mathrm{NO}_{x}\right)$ using modified Griess reaction as described by Miranda et al. [18]. The test involved preparation of Griess-I (1\% sulphanilamide $\mathrm{w} / \mathrm{v}$ in $5 \% \mathrm{HCL})$ and Griess-II $(0.1 \% \mathrm{~N}$ I-naphthyl ethylenediamine dihydrochloride w/v in milli-Q water). The reagents were made fresh and filtered before use. The chemicals were purchased from Sigma Chemical Co., St. Louis, MI, USA. $50 \mu \mathrm{L}$ of test culture supernatant and standards (sodium nitrite at 1.56, 3.12, 6.25, 12.5, 25, $50,100 \mu \mathrm{M})$ prepared in culture medium was pipetted out into a 96-well microtitre plate and blank wells contained culture media only. The tests, blanks, and standards were run in triplicates. $50 \mu \mathrm{L}$ Griess I ( $1 \%$ sulphanilamide) was added to each well and held at room temperature for 5 minutes. $50 \mu \mathrm{L}$ Griess II was then added to each well and plates were incubated at $37^{\circ} \mathrm{C}$ for $30 \mathrm{~min}$. After incubation, the absorbance was read at $540 \mathrm{~nm}$ wavelength in ELISA plate reader (Microscan MS-5608A). The concentration was calculated from the standard curve using linear regression equation. Detection limit of $\mathrm{NO}$ was $1.56 \mu \mathrm{M}$. Inter-assay and intra assay difference was $3.4 \%$ and $4.62 \%$, respectively.

The data analysis was performed using Systat 12 software package 2007 (Systat Software Inc. 1735 Technology Dr., Ste. 430, San Jose, CA 95110, USA). Analysis of variance of the data was performed using three-way ANOVA with variables age, sex, and concentration included in the model as fixed effects and Tukey's honestly significant difference test was employed. Values are presented as mean \pm S.E. Graphs and charts were prepared in Microsoft Excel 2007.

\section{Results}

3.1. Effects of Sex Steroids on Lymphocyte Proliferation. The effect of four different levels of estradiol (10, 100, 500, and $1000 \mathrm{pg} / \mathrm{mL}$ ) on lymphocyte proliferation response that was calculated as proliferation index (PI), in buffalo lymphocytes cultured in vitro, is presented in Table 1. Proliferation response, irrespective of concentration of estradiol added, was inhibited by 3 and 1\%, respectively, in lymphocytes from both male $(0.97 \pm 0.01)$ and female $(0.99 \pm 0.01)$ buffaloes that did not differ significantly. However, significant $(P<$ 0.001 ) variation between age groups and treatment levels was observed in the present study. Estrogen was found inhibiting proliferation in group-I and group-II buffaloes by $5 \%$ as compared to group-III post pubertal buffaloes where it stimulated the proliferation to the level of $4 \%$. Among all the groups, post pubertal female buffaloes registered the highest $(P<0.05)$ PI $(1.09 \pm 0.03)$ with estrogen treatment. Among the four concentrations of estrogen, $100 \mathrm{pg} / \mathrm{mL}$ registered significant $(P<0.001)$ stimulatory effect on PI $(1.05 \pm 0.02)$ to the level of $5 \%$ as compared to $1000 \mathrm{pg} / \mathrm{mL}(0.93 \pm 0.02)$ and $10 \mathrm{pg} / \mathrm{mL}(0.95 \pm 0.01)$ that instead inhibited lymphocyte proliferation by $7 \%$ and $5 \%$ respectively.

Estrogen treatment of the lymphocytes collected from cyclic buffaloes on day 10 registered significantly $(P<0.05)$ higher stimulatory effect on PI to as high as $10 \%(1.10 \pm$ $0.03)$ as compared to $3 \%(1.03 \pm 0.01)$ on day 0 of estrous cycle. Among the estrogen concentrations, 1000, 500, and $100 \mathrm{pg} / \mathrm{mL}$ stimulated the lymphocyte proliferation $(1.12$, 1.10 , and 1.07$)$ significantly $(P<0.05)$ to the level of $12 \%$, $10 \%$, and $7 \%$, respectively, whereas low level $(10 \mathrm{pg} / \mathrm{mL})$ inhibited proliferation $(0.99 \pm 0.03)$ up to $1 \%$ in cyclic buffaloes. Thus, in cycling females only low level of estrogen was found to be inhibitory to lymphocyte proliferation while all other concentrations were stimulatory.

Effects of progesterone treatment on in vitro proliferation of buffalo lymphocytes registered in present study are presented in Table 2.

Though progesterone inhibited lymphocyte proliferation significantly $(P<0.01)$ in both males and females, the inhibitory effect was severe in males $(0.90 \pm 0.01)$ to the level of $10 \%$ as compared to females $(0.97 \pm 0.01)$ only $3 \%$. There was no significant difference in the effects of progesterone between different age groups of buffaloes. Progesterone inhibitory effects were significantly $(P<0.001)$ dose-dependent and PI was inversely proportional to the progesterone concentration. The highest concentration of progesterone $(1000 \mathrm{ng} / \mathrm{mL})$ inhibited proliferation $(0.81 \pm$ $0.02)$ by $19 \%$ whereas the lowest $(10 \mathrm{ng} / \mathrm{mL})$ registered 
TABLE 2: Dose dependent effect of progesterone on lymphocyte proliferation in vitro in Murrah buffaloes of different sex and age.

\begin{tabular}{|c|c|c|c|c|c|c|c|c|}
\hline \multirow{2}{*}{ Age group } & \multirow{2}{*}{ Sex } & \multicolumn{4}{|c|}{ Progesterone concentration $(\mathrm{ng} / \mathrm{mL})$} & \multirow{2}{*}{$\begin{array}{c}\text { Sex* } \\
\text { group mean }\end{array}$} & \multirow{2}{*}{ Group mean } & \multirow{2}{*}{ Sex mean } \\
\hline & & 10 & 100 & 500 & 1000 & & & \\
\hline \multirow{2}{*}{ Group-I } & Male & $0.98 \pm 0.03$ & $0.90 \pm 0.03$ & $0.92 \pm 0.02$ & $0.86 \pm 0.01$ & $0.91 \pm 0.01$ & \multirow{2}{*}{$0.92 \pm 0.01$} & \multirow{2}{*}{$\begin{array}{l}0.90 \pm 0.01 \\
(\text { Male })\end{array}$} \\
\hline & Female & $0.99 \pm 0.07$ & $0.96 \pm 0.04$ & $0.93 \pm 0.02$ & $0.83 \pm 0.04$ & $0.92 \pm 0.02$ & & \\
\hline \multirow{2}{*}{ Group-II } & Male & $1.09 \pm 0.07$ & $1.07 \pm 0.05$ & $0.87 \pm 0.03$ & $0.73 \pm 0.02$ & $0.94 \pm 0.03$ & \multirow{2}{*}{$0.94 \pm 0.01$} & \multirow{4}{*}{$\begin{array}{l}0.97 \pm 0.01 \\
\text { (Female) }\end{array}$} \\
\hline & Female & $1.01 \pm 0.01$ & $1.00 \pm 0.04$ & $0.89 \pm 0.02$ & $0.76 \pm 0.01$ & $0.94 \pm 0.02$ & & \\
\hline \multirow{2}{*}{ Group-III } & Male & $1.06 \pm 0.05$ & $0.89 \pm 0.04$ & $0.77 \pm 0.04$ & $0.71 \pm 0.05$ & $0.86 \pm 0.03$ & \multirow{2}{*}{$0.96 \pm 0.01$} & \\
\hline & Female & $1.14 \pm 0.07$ & $1.07 \pm 0.05$ & $1.05 \pm 0.05$ & $0.99 \pm 0.03$ & $1.06 \pm 0.02$ & & \\
\hline \multicolumn{2}{|c|}{ Treatment mean } & $1.06^{\mathrm{a}} \pm 0.02$ & $0.98^{\mathrm{b}} \pm 0.02$ & $0.90^{c} \pm 0.02$ & $0.81^{\mathrm{d}} \pm 0.02$ & & & \\
\hline
\end{tabular}

Values with different superscript within same row differ significantly $(P<0.05)$. CD at $t 5 \%$ : sex: 0.03 , treatment: 0.05 , sex* group: 0.06 and sex* group* treatment: 0.123 .

TABLE 3: Dose-dependent effect of testosterone on lymphocyte proliferation in vitro in buffaloes of different sex and age.

\begin{tabular}{|c|c|c|c|c|c|c|c|c|}
\hline \multirow{2}{*}{ Age group } & \multirow{2}{*}{ Sex } & \multicolumn{4}{|c|}{ Testosterone concentration $(\mathrm{ng} / \mathrm{mL})$} & \multirow{2}{*}{$\begin{array}{l}\text { Sex* } \\
\text { group mean }\end{array}$} & \multirow{2}{*}{ Group mean } & \multirow{2}{*}{ Sex mean } \\
\hline & & 0.10 & 1 & 10 & 100 & & & \\
\hline \multirow{2}{*}{ Group-I } & Male & $1.27 \pm 0.06$ & $1.04 \pm 0.04$ & $1.18 \pm 0.04$ & $1.02 \pm 0.04$ & $1.13 \pm 0.03$ & \multirow{2}{*}{$1.04 \pm 0.017$} & \multirow{2}{*}{$\begin{array}{l}1.03 \pm 0.01 \\
\text { (Male) }\end{array}$} \\
\hline & Female & $0.97 \pm 0.03$ & $0.94 \pm 0.02$ & $0.94 \pm 0.02$ & $0.98 \pm 0.03$ & $0.96 \pm 0.01$ & & \\
\hline \multirow{2}{*}{ Group-II } & Male & $0.95 \pm 0.03$ & $1.05 \pm 0.03$ & $0.93 \pm 0.04$ & $0.91 \pm 0.03$ & $0.96 \pm 0.02$ & \multirow{2}{*}{$1.03 \pm 0.017$} & \multirow{4}{*}{$\begin{array}{l}1.05 \pm 0.01 \\
\text { (Female) }\end{array}$} \\
\hline & Female & $1.11 \pm 0.05$ & $1.140 \pm 0.04$ & $1.08 \pm 0.05$ & $1.07 \pm 0.03$ & $1.10 \pm 0.02$ & & \\
\hline \multirow{2}{*}{ Group-III } & Male & $0.94 \pm 0.05$ & $1.05 \pm 0.05$ & $1.06 \pm 0.03$ & $0.90 \pm 0.03$ & $0.99 \pm 0.02$ & \multirow{2}{*}{$1.04 \pm 0.017$} & \\
\hline & Female & $1.06 \pm 0.06$ & $1.08 \pm 0.05$ & $1.12 \pm 0.05$ & $1.14 \pm 0.09$ & $1.10 \pm 0.03$ & & \\
\hline \multicolumn{2}{|c|}{ Treatment mean } & $1.05 \pm 0.02$ & $1.05 \pm 0.02$ & $1.05 \pm 0.02$ & $1.00 \pm 0.02$ & & & \\
\hline
\end{tabular}

CD at $t 5 \%$ : sex: 0.03 , group: 0.04 , sex* group: 0.06 , sex* group* treatment: 0.13 .

stimulatory effect $(1.058 \pm 0.02)$ of $6 \%$. Among all groups, group-III post pubertal female buffaloes registered highest $(P<0.01)$ proliferation $(1.065 \pm 0.02)$ and group-III post pubertal males the lowest $(0.86 \pm 0.03)$ when treated with progesterone.

The progesterone effects were not significantly different between the lymphocytes from the day 0 and day 10 of reproductive cycle. However, dose dependent effect of progesterone on proliferation was significant $(P<0.01)$ with highest concentration $1000 \mathrm{ng} / \mathrm{mL}$ progesterone inhibiting proliferation $(0.976 \pm 0.02)$ by $2 \%$ and $10 \mathrm{ng} / \mathrm{mL}$ stimulated proliferation $(1.103 \pm 0.02)$ by $10 \%$. The trend in lymphocyte proliferation with decreased dose of progesterone was linear.

The effects of testosterone treatment on in vitro proliferation of buffalo lymphocytes of different sex and age are presented in Table 3. Proliferation index was not found to be different in the two sexes in response to testosterone supplementation in the culture. Males and females registered stimulation in proliferation $(1.026 \pm 0.01$ and $1.05 \pm 0.01)$ to the level of 2 and $5 \%$, respectively. Testosterone in different concentration did not affect the lymphocyte proliferation significantly. The highest concentration of $100 \mathrm{ng} / \mathrm{mL}$ neither stimulated nor inhibited proliferation $(1.00 \pm 0.02)$. Other treatments of 10,1 , and $0.1 \mathrm{ng} / \mathrm{mL}$ concentration did stimulate proliferation $(1.05 \pm 0.02,1.052 \pm 0.02$, and $1.048 \pm 0.02$ ) equally to the level of $5 \%$ which was statistically nonsignificant between the concentrations. Testosterone significantly $(P<0.01)$ inhibited proliferation by $4 \%$ in group-II males but stimulated by $13 \%$ in group-I males, irrespective of testosterone concentration. Contrary to this, testosterone significantly $(P<0.01)$ inhibited proliferation $(0.958 \pm 0.01)$ by $5 \%$ in group-I females but stimulated $(1.101 \pm 0.03)$ by $10 \%$ in group-III post pubertal females.

There was no significant effect of testosterone on lymphocyte proliferation index in cycling buffaloes. However, proliferation was comparatively low in lymphocytes from day $0(1.049 \pm 0.03)$ as compared to day $10(1.104 \pm$ 0.03 ) of estrous cycle when treated with testosterone. The testosterone in all its concentrations stimulated proliferation to the level of $10 \%(1.104 \pm 0.04)$ at $10 \mathrm{ng} / \mathrm{mL}$ and $5 \%$ $(1.049 \pm 0.04)$ at $0.01 \mathrm{ng} / \mathrm{mL}$ concentration in cyclic buffaloes.

3.2. Nitric Oxide Levels in Culture Supernatant. Nitric oxide was evaluated in supernatant collected 36 hours after lymphocyte culture (Figure 1). Males produced significantly $(P<0.001)$ higher $(8.52 \pm 0.39 \mu \mathrm{M} / \mathrm{L})$ NO in culture than females $(6.13 \pm 0.39 \mu \mathrm{M} / \mathrm{L})$. The difference was also significant $(P<0.05)$ among the three groups with lowest in group-III $(6.23 \pm 0.48 \mu \mathrm{M} / \mathrm{L})$, followed by group-II $(8.07 \pm$ $0.48 \mu \mathrm{M} / \mathrm{L})$ and group-I $(7.68 \pm 0.48 \mu \mathrm{M} / \mathrm{L})$. Among all groups, group-II male buffaloes registered the highest $(9.89 \pm$ $1.18 \mu \mathrm{M} / \mathrm{L})$ and group-III female buffaloes the lowest $(4.87 \pm$ $0.42 \mu \mathrm{M} / \mathrm{L}$ ) levels of nitric oxide in culture supernatant. In cyclic buffaloes the nitric oxide concentration in culture supernatant did not differ significantly with the stage of estrous cycle and was $5.20 \pm 0.29$ and $4.88 \pm 0.41 \mu \mathrm{M} / \mathrm{L}$ on day 0 (estrus) and day 10 (diestrus), respectively (Figure 1). 


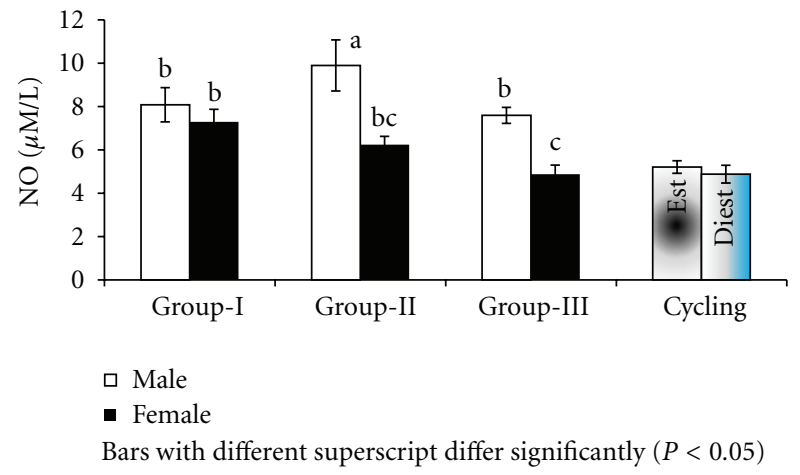

FIGURE 1: NO culture supernatant in Murrah buffaloes of different sex, age, and stage of cycle.

Significantly $(P<0.001)$ higher levels of nitric oxide were recorded in culture supernatant of males $(9.73 \pm 0.30 \mu \mathrm{M} / \mathrm{L})$ than females $(6.75 \pm 0.30 \mu \mathrm{M} / \mathrm{L})$ after 36 hours of culture supplemented with estradiol. The NO levels in culture supernatants supplemented with estradiol were significantly $(P<$ 0.001) different between age groups with group-I buffalo lymphocytes registering NO as high as $11.36 \pm 0.37 \mu \mathrm{M} / \mathrm{L}$ followed by group-II and group-III (Figure 2). Among the groups lymphocytes from group-I males registered highest NO $(14.01 \mu \mathrm{M} / \mathrm{L})$ in culture supernatant (Figure 2). There was significant $(P<0.05)$ effect of different concentrations of estrogen on nitric oxide levels in culture supernatant; however, NO levels were maximum $(8.77 \pm 0.74 \mu \mathrm{M} / \mathrm{L})$ at $100 \mathrm{pg} / \mathrm{mL}$ concentration of estrogen and minimum at $10 \mathrm{pg} / \mathrm{mL}$ level (Figure 3).

In cyclic buffaloes, NO in culture supernatant of day 10 (diestrous) lymphocytes was $(5.30 \pm 0.44 \mu \mathrm{M} / \mathrm{L})$ significantly $(P<0.001)$ higher than $(3.47 \pm 0.38 \mu \mathrm{M} / \mathrm{L})$ day 0 (estrous) lymphocytes. Similarly different concentrations of estrogen in culture system had significant $(P<0.001)$ effect on NO in culture supernatant in cyclic buffaloes. Significantly higher levels of $\mathrm{NO}(5.82 \pm 0.39 \mu \mathrm{M} / \mathrm{L}$ and $5.51 \pm 0.39 \mu \mathrm{M} / \mathrm{L})$ were recorded at $100 \mathrm{pg} / \mathrm{mL}$ and $500 \mathrm{pg} / \mathrm{mL}$ estradiol, respectively, as compared to $(3.43 \pm 0.93$ and $2.79 \pm 0.39 \mu \mathrm{M} / \mathrm{L})$ at $1000 \mathrm{pg} / \mathrm{mL}$ and $10 \mathrm{pg} / \mathrm{mL}$ estradiol, respectively, in cyclic buffaloes (Figure 3 ).

Significant $(P<0.001)$ difference in levels of nitric oxide in culture supernatant supplemented with different concentrations of progesterone was registered between the sexes $(6.58 \pm 0.23$ and $4.97 \pm 0.23 \mu \mathrm{M} / \mathrm{L}$ in males and females resp.) and between the age groups $(4.50 \pm 0.28$, $6.56 \pm 0.28$, and $6.24 \pm 0.28 \mu \mathrm{M} / \mathrm{L}$ in group-I, group-II, $\&$ group-III buffaloes, resp.). Among the groups, group-II males registered highest $(P<0.05)$ levels of NO in culture supernatant where as group-I females the lowest (Figure 4). Similarly nitric oxide levels in culture supernatant differed significantly $(P<0.01)$ between various concentrations of progesterone treatment (Figure 5).

In cyclic buffaloes, phases of cycle influenced significantly the NO production in culture system. Lymphocytes from day 10 registered significantly $(P<0.01)$ higher $(5.68 \pm$ $0.40 \mu \mathrm{M} / \mathrm{L}) \mathrm{NO}$ in culture supernatant as compared to

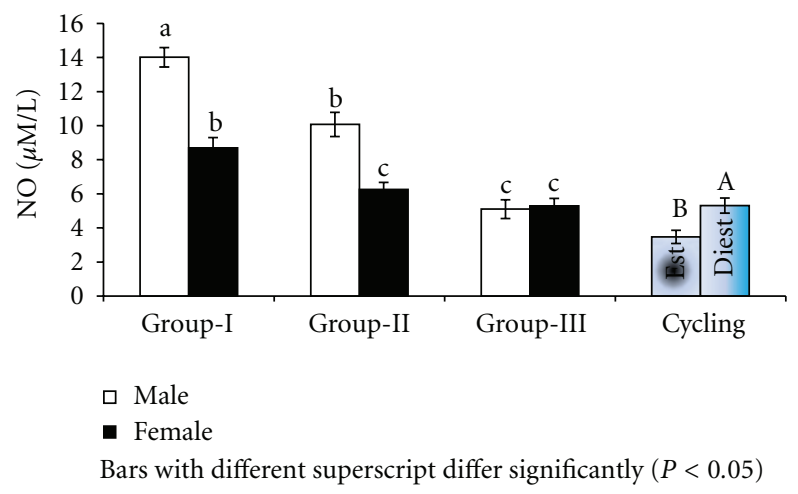

FIGURE 2: NO in culture supernatant supplemented with estradiol in Murrah buffaloes of different sex, age, and stage of cycle.

day $0(3.98 \pm 0.40 \mu \mathrm{M} / \mathrm{L})$ (Figure 4). There was significant $(P<0.01)$ decline in NO production with increasing concentrations of progesterone supplementation with highest $\mathrm{NO}$ at $10 \mathrm{ng} / \mathrm{mL}$ progesterone followed by 100,500 , and $1000 \mathrm{ng} / \mathrm{mL}$ progesterone respectively in cyclic buffaloes (Figure 5).

Analysis of variance revealed significant influence of sex on nitric oxide production in culture supernatant supplemented with testosterone and male and female buffaloes on an average, which produced $7.13 \pm 0.23$ and $7.54 \pm 0.23 \mu \mathrm{M} / \mathrm{L}$ NO, respectively. Further, NO in culture supernatant was significantly $(P<0.05)$ high $(7.98 \pm 0.29 \mu \mathrm{M} / \mathrm{L})$ in groupII buffaloes as compared to group-III $(7.08 \pm 0.29)$ and group-I $(6.96 \pm 0.29 \mu \mathrm{M} / \mathrm{L})$. Among the all groups, groupII male buffaloes recorded the highest $(P<0.01)$ NO whereas group-I males the lowest (Figure 6). The levels did not vary significantly in culture supernatant in response to different levels of testosterone (Figure 7). However, the levels were comparatively higher $(7.99 \pm 0.41 \mu \mathrm{M} / \mathrm{L})$ with $10 \mathrm{ng} / \mathrm{mL}$ supplementation.

In cyclic buffaloes, the estrous and diestrous phases of reproductive cycle did not significantly influence NO production in culture supplemented with different concentrations of testosterone and mean levels of $\mathrm{NO}$ in supernatant were $7.20 \pm 0.35$ and $6.62 \pm 0.35 \mu \mathrm{M} / \mathrm{L}$ in day 10 and day 0 lymphocyte culture, respectively (Figure 6). However, among the testosterone concentrations, NO production at 0.1 and $100 \mathrm{ng} / \mathrm{mL}$ concentrations was similar and significantly lower than at $1 \mathrm{ng} / \mathrm{mL}$ and $10 \mathrm{ng} / \mathrm{mL}$ (Figure 7).

\section{Discussion}

In vitro lymphocyte proliferation was measured in response to supplementation of different doses of estrogen in culture. Estrogen inhibited proliferation slightly in lymphocytes of group-I and group-II but stimulated in group-III buffaloes of either sex. However, among four concentrations of estradiol, $100 \mathrm{pg} / \mathrm{mL}$ was stimulatory in buffaloes of all ages of either sex as compared to 1000 and $10 \mathrm{pg} / \mathrm{mL}$. These findings reflect the dose-dependent effect of estrogen on lymphocyte 


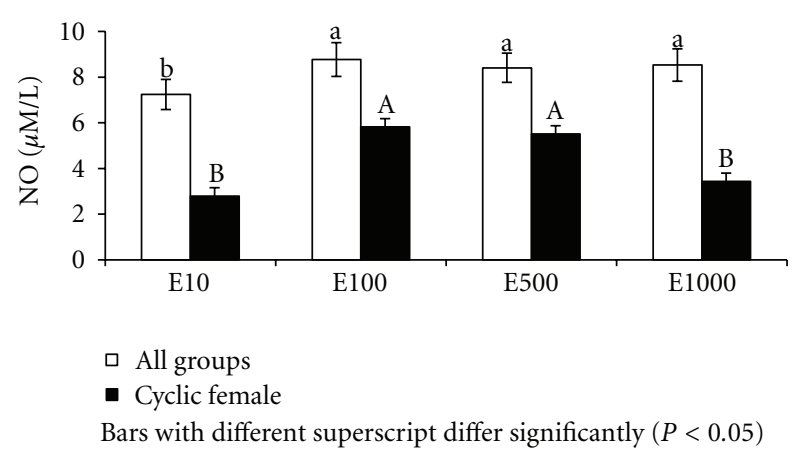

FIGURE 3: NO in culture supernatant supplemented with different levels of estradiol in Murrah buffaloes.

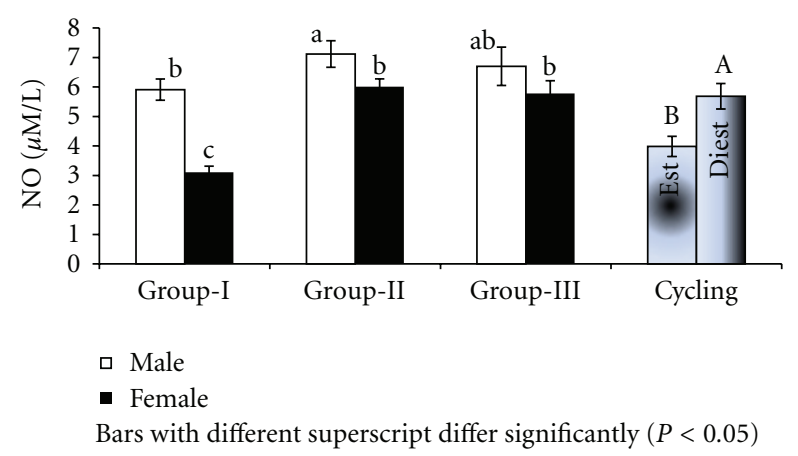

FIGURE 4: NO in culture supernatant supplemented with progesterone in Murrah buffaloes.

proliferation. Possibly certain levels of estrogen are immunostimulatory and enhance cell mediated immunity but at the same time very high doses are immunosuppressive. An interesting finding was that, in post pubertal females, estrogen at higher concentration also had stimulatory effect on lymphocyte proliferation. There is no consistency in available reports on lymphocyte proliferation delineating similar type of response in relation to estrogen in different animals. Marco et al. [19] reported inhibitory effects of estradiol on lymphocyte proliferation in both males and females at $50 \mathrm{nM}$ concentration that upholds the present findings. Athreya et al. [20] used 0.3 to $3 \mathrm{ng} / \mathrm{mL}$ of estradiol and reported no consistent effects on human PBMCs proliferation in vitro. Similarly Holdstock et al. [21] used estradiol at $40 \mathrm{ng} / \mathrm{mL}$ in culture and reported no significant effect of it on mitogeninduced proliferation in humans. Bilbo and Nelson [12] reported stimulatory effect of estrogen at all levels on lymphocyte proliferation in vitro in hamsters, contrary to many other studies. All these findings suggest the charisma of species variation in the effects of estradiol on cellmediated immunity. Further, estrogen had different effects on lymphocyte proliferation from estrous and diestrous stage of reproductive cycle with significantly higher stimulation in diestrous phase lymphocytes than estrous. Since groupIII females in present study were actually progesterone dominated therefore, to counteract the negative effects of immunosuppressive progesterone, estrogen even at higher concentrations actually might have boosted the blastogenic

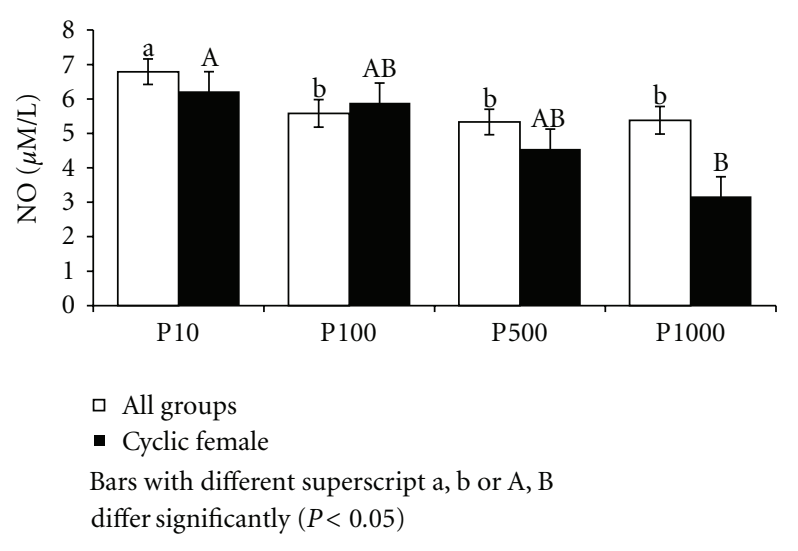

FIGURE 5: NO in culture supernatant supplemented with different levels of progesterone in Murrah buffaloes.

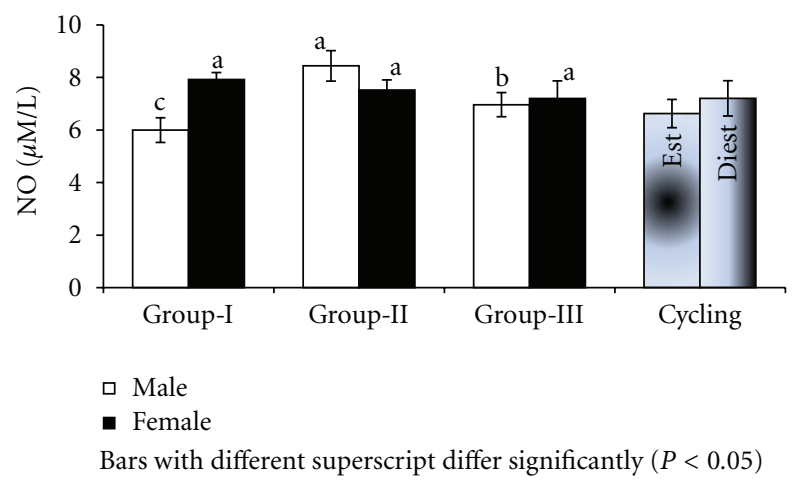

FIGURE 6: NO in culture supernatant supplemented with testosterone in Murrah buffaloes of different sex, age, and stage of cycle.

activity of lymphocytes in diestrous cyclic buffaloes rather than inhibiting as was true for other nonprogesterone phases like estrous. These present results are comparable to the findings of Sugiura et al. [22] who reported significantly enhanced response of dog PBMNCs collected in anestrus to PYO-252 upon the addition of estradiol-17 beta to the culture. There are reports of presence of steroid hormone receptors in immune cells [23-27] and presence or absence, upregulation or downregulation of receptors may be the probable reason for the varied responses of lymphocytes to estrogen treatment. There is possibility of different outcome of genomic and nongenomic pathway of steroid actions on lymphocyte blastogenesis and depending upon the receptor concentration stimulation or inhibition of lymphocyte proliferation may be regulated. Therefore, it seems important to investigate the receptor expression in immune cells at different proliferation responses to arrive at a comprehensible conclusion.

Progesterone supplementation at different concentrations in all buffalo groups of either sex inhibited proliferation with more severe inhibition in males $(10 \%)$ as compared to females $(3 \%)$. This sex-dependent variability in progesterone effects may probably be due to the adaptation of lymphocytes to progesterone because of being exposed to 


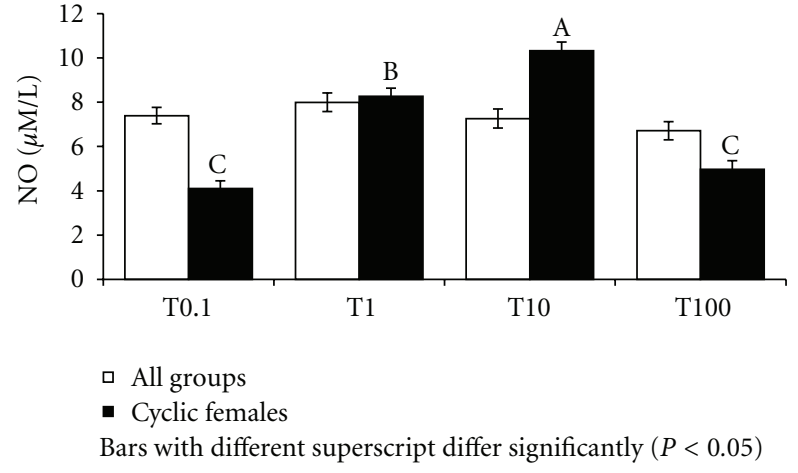

FIGURE 7: NO in culture supernatant supplemented with different levels of testosterone in Murrah buffaloes.

it in females. There was an inverse relationship between the dose and proliferation index. The highest concentration of progesterone $(1000 \mathrm{ng} / \mathrm{mL})$ inhibited proliferation by $19 \%$ whereas the lowest $(10 \mathrm{ng} / \mathrm{mL})$ registered stimulatory effect of $6 \%$. These findings are in partial agreement with those reported by Marco et al. [19] in mice who reported inhibitory effect of progesterone only in females. There are several reports which indicate immunosuppressive effects of progesterone. R. Druckmann and M. A. Druckmann [28] reported that progesterone up regulated progesterone receptors on lymphocytes in placenta and was responsible for production of progesterone-induced blocking factor which favours conception and disfavours the rejection of conceptus. $\mathrm{Su}$ et al. [29] reported inhibitory effects of progesterone on immune response to lipopolysaccharide (LPS) through modulating Toll-like receptor (TLR) signalling. WulsterRadcliffe et al. [9] in gilts and Kaushic et al. [6] in rodents reported that exogenous progesterone increased the risk of development of diseases indicating inhibitory effects of progesterone on cell-mediated immune responses. Sugiura et al. [22] examined the proliferative response of PBMNCs to PYO-252 and reported significantly decreased response in the first half (day 10) of estrous cycle, but increased in proestrous/estrous and these responses were significantly suppressed in the presence of progesterone. All these reports suggest the immunosuppressive effects of progesterone and in principle confirm the present finding in buffaloes with progesterone having inhibitory effect on cellmediated immunity.

In current investigation, testosterone treatment stimulated lymphocyte proliferation in both males and females to the tune of 2 and 5\%, respectively, with no significant dosedependent effect. Testosterone treatment in lymphocyte culture did not yield any dependable and lucid effects either at any particular dose or in any age group. In group-I males it stimulated proliferation at all concentrations of testosterone with maximum at $0.1 \mathrm{ng} / \mathrm{mL}$ but in case of group-I female it inhibited proliferation at all concentrations of testosterone. In group-II males contrary to group-I males, testosterone inhibited proliferation except at $1 \mathrm{ng} / \mathrm{mL}$ concentration but at the same time in group-II females it stimulated proliferation at all concentrations of testosterone with maximum at
$1 \mathrm{ng} / \mathrm{mL}$. Whereas in group-III post pubertal males picture was same as that of group-II males but in group-III females, testosterone stimulated proliferation at all concentrations with maximum at $100 \mathrm{ng} / \mathrm{mL}$. With these varied effects of testosterone, it is hard to arrive at any definitive conclusion. It may be possible that the lymphocytes possess the capability to convert testosterone into estrogen, which may govern the proliferation in adult buffaloes. This option may be working since we got similar observations with testosterone and estrogen in post pubertal female lymphocytes. Benten et al. [30] have demonstrated a membrane testosterone receptor on lymphocyte enabling $\mathrm{T}$ cells a nongenomic response to testosterone. Therefore, research in steroid receptors and converting enzymes in lymphocytes is warranted. Bilbo and Nelson [12] in hamsters found that both testosterone as well as estradiol is stimulatory to lymphocyte proliferation, whereas Marco et al. [19] in mice reported no significant effect of testosterone on lymphocyte proliferation or cytokine secretion. Roden et al. [13] reported improved immune responses including lymphocyte proliferation on deprivation of testosterone in rodent model. Duffy et al. [31] in wild male and female starling birds reported that implant of testosterone significantly reduced humoral immunity in both males and females. All these reports indicate species differences in testosterone effects on immune responses. Present findings revealed testosterone as stimulatory to lymphocyte proliferation in buffaloes of all ages and sexes at least at $1 \mathrm{ng} / \mathrm{mL}$ concentration. Although, current knowledge of sex steroid hormone effects on immune function is relatively limited to that of mice, rats, and humans [32, 33], the results of the current study in buffaloes suggest a unique role for the sex steroids in influencing immune functions that may have evolved along with the distinct natural history of these animals.

\subsection{Nitric Oxide in Culture Supernatant Cultured with Sex} Steroids. Sex and age bias in NO production by lymphocytes in culture was evident in present study. Significantly high levels of $\mathrm{NO}$ were found in culture supernatant of males as compared to females treated with estrogen. Among the groups, group-I buffaloes had more $\mathrm{NO}$ in culture as compared to group-II and III. However, production rate was not affected by increasing dose of estrogen in culture. The proliferation was higher in group-III where NO was lowest suggesting inverse relationship between PI and nitric oxide production in culture and probably estrogen affected proliferation through NO levels in lymphocyte culture. However, the NO in culture supernatant of day 10 lymphocytes was significantly higher than day 0 while proliferation was also significantly high at diestrous than estrous phase. NO has been reported to be secreted by lymphocytes [34, 35] and blood leukocytes [36] in cattle. NO is liberated either spontaneously or after cleavage by ectoenzymes found on $\mathrm{T}$ and B lymphocytes in bovines [35, 37].

Nitric oxide in lymphocyte culture treated with different concentrations of progesterone was significantly high in males as compared to females. Among the groups, significantly high levels of NO in culture supernatant were 
found in group-III and least in group-I buffaloes. In cyclic buffaloes, diestrous phase lymphocytes produced more NO than estrous phase, treated with progesterone. Similarly the nitric oxide levels in supernatant differed between the concentrations of progesterone with lowest $\mathrm{NO}$ at highest progesterone concentration. The same trend was also observed in lymphocyte proliferation. This suggested that progesterone probably has no direct effect on NO production by lymphocytes and as such more proliferation is accompanied with more NO.

NO in lymphocyte culture supernatant at any level of testosterone did not show any significant difference between sexes with male and female buffaloes on an average, producing $7.13 \pm 0.23$ and $7.54 \pm 0.23 \mu \mathrm{M} / \mathrm{L} \mathrm{NO}$, respectively, in culture. This indicated that the lymphocytes obtained from female animals were equally responsive to testosterone as males. However, levels tended to be significantly $(P<$ 0.05 ) high in group-II buffaloes as compared to groupI and III. In general, low levels of proliferation were associated with less production of $\mathrm{NO}$ in culture in different age groups of buffaloes. Differences were not significant during different stages of estrous cycle which suggested that variations in the immune responses during estrous cycle were not related to testosterone as was evident through PI also.

Since it happens to be the first report to register NO in culture supernatant of lymphocytes from buffaloes of different sex and age with sex steroid treatment, it needs further investigation before arriving at any final conclusion on relationship of sex steroids, NO, and lymphocyte proliferation.

\section{Conclusion}

Effect of female sex steroids on lymphocyte proliferation in vitro was found to be existing. Estradiol effects were dose dependent too, and high as well as too low levels of estradiol were inhibitory to lymphocyte proliferation. Progesterone was found to be inhibiting lymphocyte proliferation and there was inverse relationship between progesterone dose and lymphocyte proliferation. Testosterone did not show any consistent and lucid effects on lymphocyte proliferation, nor did it inhibit proliferation at any dose level. The proliferation was higher in group-III where NO was lowest suggesting inverse relationship between PI and nitric oxide production in culture and probably estrogen affected proliferation through NO levels in lymphocyte culture. NO was not the candidate mediator of effects of all sex steroids in lymphocyte proliferation. NO levels in supernatant differed between the concentrations of progesterone with lowest $\mathrm{NO}$ at highest progesterone concentration and lowest proliferation. This suggested that progesterone probably has no direct effect on NO production by lymphocytes and as such more proliferation is accompanied with more NO. No significant difference in NO culture supernatant was observed at different concentrations of estradiol or testosterone.

\section{References}

[1] S. A. Ahmed, W. J. Penhale, and N. Talal, "Sex hormones, immune responses, and autoimmune diseases. Mechanisms of sex hormone action," American Journal of Pathology, vol. 121, no. 3, pp. 531-551, 1985.

[2] Z. I. Rajput, S. H. Hu, A. G. Arijo, M. Habib, and M. Khalid, "Comparative study of Anaplasma parasites in tick carrying buffaloes and cattle," Journal of Zhejiang University, vol. 6, no. 11, pp. 1057-1062, 2005.

[3] M. Ramzan, M. Akhtar, F. Muhammad et al., "Seroprevalence of Toxoplasma gondii in sheep and goats in Rahim Yar Khan (Punjab), Pakistan," Tropical Animal Health and Production, vol. 41, no. 7, pp. 1225-1229, 2009.

[4] M. Cutolo and R. L. Wilder, "Different roles for androgens and estrogens in the susceptibility to autoimmune rheumatic diseases," Rheumatic Disease Clinics of North America, vol. 26, no. 4, pp. 825-839, 2000.

[5] C. R. Wira, C. Kaushic, and J. Richardson, "Role of sex hormones and cytokines in regulating the mucosal immune system in the female reproductive trac," in Mucosal Immunology, P. L. Ogra, Ed., pp. 1449-1461, Academic Press, San Diego, Calif, USA, 1999.

[6] C. Kaushic, F. Zhou, A. D. Murdin, and C. R. Wira, "Effects of estradiol and progesterone on susceptibility and early immune responses to Chlamydia trachomatis infection in the female reproductive tract," Infection and Immunity, vol. 68, no. 7, pp. 4207-4216, 2000.

[7] H. D. White, K. M. Crassi, A. L. Givan et al., "CD3+CD8+ CTL activity within the human female reproductive tract influence of stage of the menstrual cycle and menopause," Journal of Immunology, vol. 158, no. 6, pp. 3017-3027, 1997.

[8] A. A. Ramadan, G. L. Johnson, and G. S. Lewis, "Regulation of uterine immune function during the estrous cycle and in response to infectious bacteria in sheep," Journal of Animal Science, vol. 75, no. 6, pp. 1621-1632, 1997.

[9] M. C. Wulster-Radcliffe, R. C. Seals, and G. S. Lewis, "Progesterone increases susceptibility of gilts to uterine infections after intrauterine inoculation with infectious bacteria," Journal of Animal Science, vol. 81, no. 5, pp. 1242-1252, 2003.

[10] Y. Kashiwazaki, Y. Maede, and S. Namioka, "Transformation of bovine peripheral blood lymphocytes in the perinatal period," The Japanese Journal of Veterinary Science, vol. 47, no. 2, pp. 337-339, 1985.

[11] N. Lacetera, D. Scalia, U. Bernabucci et al., "Moderate summer heat stress does not modify immunological parameters of Holstein dairy cows," International Journal of Biometeorology, vol. 46, no. 1, pp. 33-37, 2005.

[12] S. D. Bilbo and R. J. Nelson, "Sex steroid hormones enhance immune function in male and female Siberian hamsters," American Journal of Physiology, vol. 280, no. 1, pp. R207-R213, 2001.

[13] A. C. Roden, M. T. Moser, S. D. Tri et al., "Augmentation of T cell levels and responses induced by androgen deprivation," The Journal of Immunology, vol. 173, no. 10, pp. 6098-6108, 2004.

[14] N. J. Olsen and W. J. Kovacs, "Effects of androgens on T and B lymphocyte development," Immunologic Research, vol. 23, no. 2-3, pp. 281-288, 2001.

[15] F. J. Young, J. A. Woolliams, J. L. Williams, E. J. Glass, R. G. O'Neill, and J. L. Fitzpatrick, "In vitro peripheral blood mononuclear cell proliferation in a crossbred cattle population," Journal of Dairy Science, vol. 88, no. 7, pp. 26432651, 2005. 
[16] R. Huozha, P. Sujata, and A. Manju, "Production of NO by Murrah buffalo lymphocytes during gestation," Research Veterinarians, vol. 21, pp. 895-899, 2010.

[17] T. R. Mosmann, "Rapid colorimetric assay for cellular growth and survival: application to proliferation and cytotoxicity assays," Journal of Immunological Methods, vol. 65, no. 1-2, pp. 55-63, 1983.

[18] K. M. Miranda, M. G. Espey, and D. A. Wink, "A rapid, simple spectrophotometric method for simultaneous detection of nitrate and nitrite," Nitric Oxide, vol. 5, no. 1, pp. 62-71, 2001.

[19] M. A. D. Marco, N. Karen, S. Gloria et al., "Immune sexual dimorphism: efect of gonadal steroids on the expression of cytokines, sex steroid receptors, and lymphocyte proliferation," Journal of Steroid Biochemistry and Molecular Biology, vol. 113, no. 1-2, pp. 57-64, 2009.

[20] B. H. Athreya, J. Pletcher, F. Zulian, D. B. Weiner, and W. V. Williams, "Subset-specific effects of sex hormones and pituitary gonadotropins on human lymphocyte proliferation in vitro," Clinical Immunology and Immunopathology, vol. 66, no. 3, pp. 201-211, 1993.

[21] G. Holdstock, B. F. Chastenay, and E. L. Krawitt, "Effects of testosterone, oestradiol and progesterone on immune regulation," Clinical and Experimental Immunology, vol. 47, no. 2, pp. 449-456, 1982.

[22] K. Sugiura, M. Nishikawa, K. Ishiguro et al., "Effect of ovarian hormones on periodical changes in immune resistance associated with estrous cycle in the beagle bitch," Immunobiology, vol. 209, no. 8, pp. 619-627, 2004.

[23] N. J. Olsen and W. J. Kovacs, "Gonadal steroids and immunity," Endocrine Reviews, vol. 17, no. 4, pp. 369-384, 1996.

[24] M. Cutolo, A. Sulli, B. Seriolo, S. Accardo, and A. T. Masi, "Estrogens, the immune response and autoimmunity," Clinical and Experimental Rheumatology, vol. 13, no. 2, pp. 217-226, 1995.

[25] B. F. Bebo Jr., J. C. Schuster, A. A. Vandenbark, and H. Offner, "Androgens alter the cytokine profile and reduce encephalitogenicity of myelin-reactive T cells," Journal of Immunology, vol. 162, no. 1, pp. 35-40, 1999.

[26] L. Danel, G. Souweine, J. C. Monier, and S. Saez, "Specific estrogen binding sites in human lymphoid cells and thymic cells," Journal of Steroid Biochemistry, vol. 18, no. 5, pp. 559$563,1983$.

[27] A. Maret, J. D. Coudert, L. Garidou et al., "Estradiol enhances primary antigen-specific CD4 $\mathrm{T}$ cell responses and Th1 development in vivo. Essential role of estrogen receptor $\alpha$ expression in hematopoietic cells," European Journal of Immunology, vol. 33, no. 2, pp. 512-521, 2003.

[28] R. Druckmann and M. A. Druckmann, "Progesterone and the immunology of pregnancy," Journal of Steroid Biochemistry and Molecular Biology, vol. 97, no. 5, pp. 389-396, 2005.

[29] L. Su, Y. Sun, F. Ma, P. Lü, H. Huang, and J. Zhou, "Progesterone inhibits Toll-like receptor 4-mediated innate immune response in macrophages by suppressing NF- $\kappa$ B activation and enhancing SOCS1 expression," Immunology Letters, vol. 125, no. 2, pp. 151-155, 2009.

[30] W. P. Benten, C. Stephan, and F. Wunderlich, "B cells express intracellular but not surface receptors for testosterone and estradiol," Steroids, vol. 67, no. 7, pp. 647-654, 2002.

[31] D. L. Duffy, G. E. Bentley, D. L. Drazen, and G. F. Ball, "Effects of testosterone on cell-mediated and humoral immunity in non-breeding adult European starlings," Behavioral Ecology, vol. 11, no. 6, pp. 654-662, 2000.
[32] L. Brabin, "Sex differentials in susceptibility to lymphatic filariasis and implications for maternal child immunity," Epidemiology and Infection, vol. 105, no. 2, pp. 335-353, 1990.

[33] C. J. Grossman, "Regulation of the immune system by sex steroids," Endocrine Reviews, vol. 5, no. 3, pp. 435-455, 1984.

[34] V. D. Dixit and N. Parvizi, "Pregnancy stimulates secretion of adrenocorticotropin and nitric oxide from peripheral bovine lymphocytes," Biology of Reproduction, vol. 64, no. 1, pp. 242248, 2001.

[35] S. J. Kirk, M. C. Regan, and C. Barbul, "Cloned murine T lymphocytes synthesize a molecule with the biological characteristics of nitric oxide synthase gene," Biochemical and Biophysical Research Communications, vol. 191, pp. 767-774, 1990.

[36] V. Boulanger, L. Bouchard, X. Zhao, and P. Lacasse, "Induction of nitric oxide production by bovine mammary epithelial cells and blood leukocytes," Journal of Dairy Science, vol. 84, no. 6, pp. 1430-1437, 2001.

[37] S. E. Henson, T. C. Nichols, V. M. Holers, and D. R. Karp, "The ectoenzyme $\gamma$-glutamyl transpeptidase regulates antiproliferative effects of S-nitrosoglutathione on human $\mathrm{T}$ and B lymphocytes," Journal of Immunology, vol. 163, no. 4, pp. 1845-1852, 1999. 

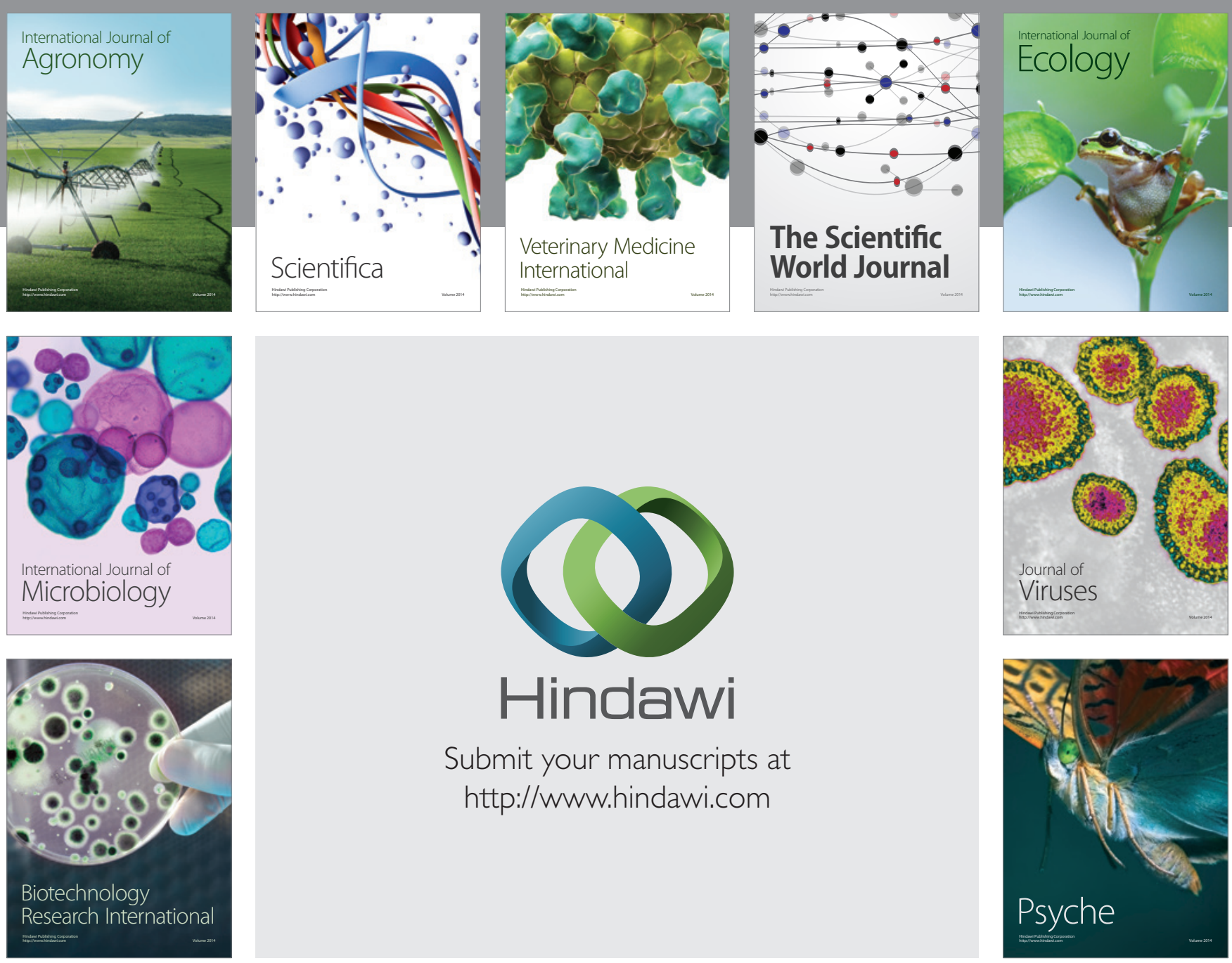

Submit your manuscripts at

http://www.hindawi.com
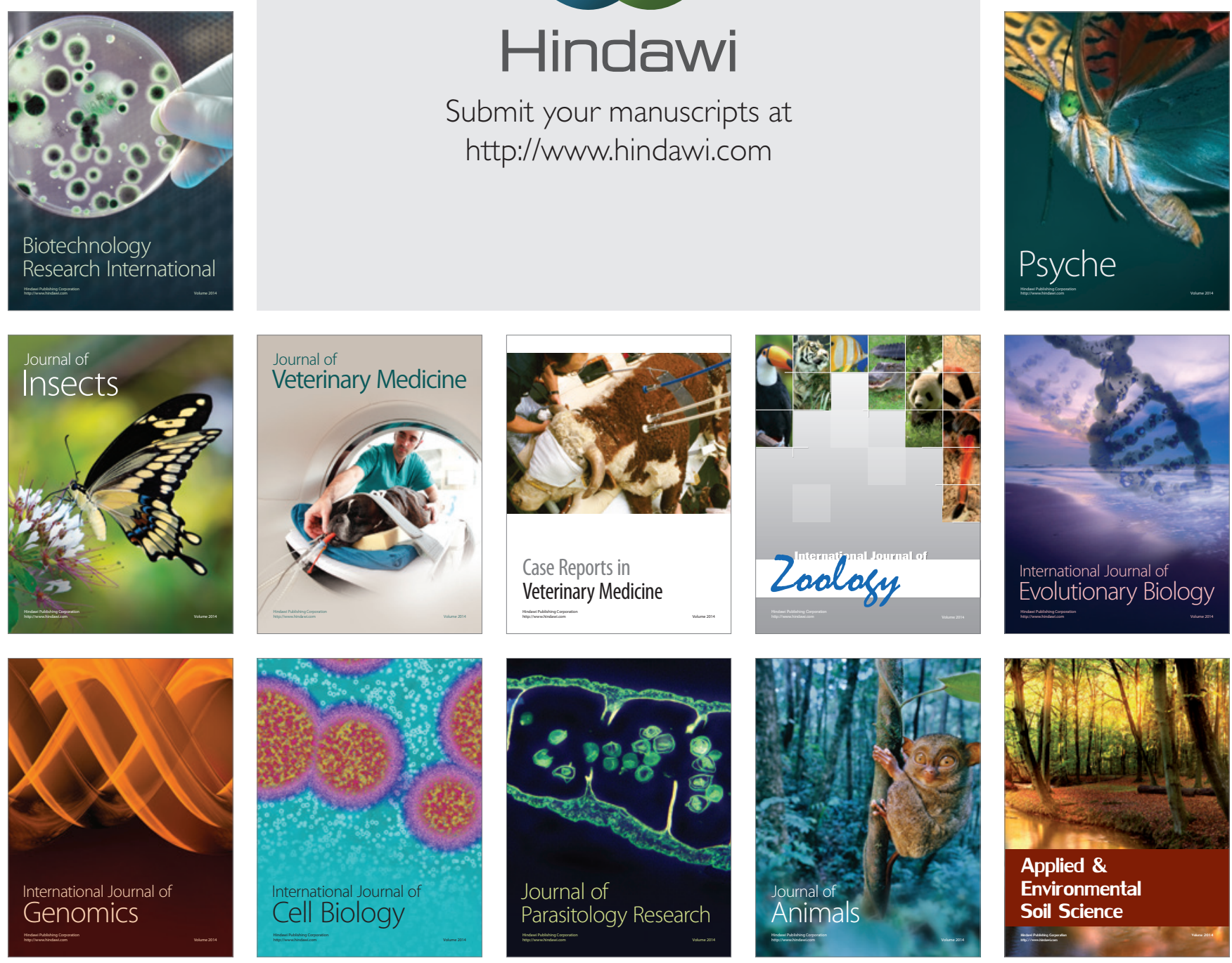